\title{
December 2011
}

The official journal of the International

Covering all areas of

human genetics

with an emphasis on

twin studies, genetic

epidemiology, psychiatric

and behavioral genetics,

and research on

multiple births in the

fields of epidemiology,

genetics, endocrinology,

fetal pathology, obstetrics

and pediatrics.

Twin Research and Human Genetics is published six times annually and issued to all financial ordinary, institutional and student members of ISTS and HGSA.

Copyright in all articles rests with authors. A limited set of permanent copyright permission licences has been granted by authors to the publisher to allow publication in this journal. Rights in the reproduction and distribution of the published articles as visual facsimiles of this published edition by either mechanical or digital means is controlled by the publisher and any distributions by CAL for copying of an author's work are due to the publisher in the first instance. All other rights in the words contained in this edition are controlled by the authors. Authors are therefore free to adapt and/or republish the words making up their own articles either online or in print.

Published for the ISTS by AUSTRALIAN ACADEMIC PRESS

32 Jeays Street, Bowen Hills,

QLD 4006, Australia.

www.australianacademicpress.com.au

\section{Articles}

The Child and Adolescent Twin Study in Sweden (CATSS)

Henrik Anckarsäter, Sebastian Lundström, Linnea Kollberg, Nora Kerekes, Camilla Palm, Eva Carlström, Niklas Långström, Patrik K. E. Magnusson, Linda Halldner, Sven Bölte, Christopher Gillberg, Clara Gumpert, Maria Råstam and Paul Lichtenstein

Returns to Education: What Do Twin Studies Control?

Kevin C. Stanek, William G. lacono and Matt McGue

The Relationship Between the Genetic and Environmental Influences on Common Externalizing Psychopathology and Mental Wellbeing

Kenneth S. Kendler, John M. Myers and Corey L. M. Keyes

Differential Age and Sex Effects in the Assessment of Major Depression: A Population-Based Twin Item Analysis of the DSM Criteria Steven H. Aggen, Kenneth S. Kendler, Thomas S. Kubarych and Michael C. Neale

A Behavioral-Genetic Study of Alexithymia and its Relationships with Trait Emotional Intelligence

Holly M. Baughman, Sara Schwartz, Julie Aitken Schermer, Livia Veselka, K. V. Petrides and Philip A. Vernon

Shorter Adult Stature Increases the Impact of Risk Factors for Cognitive Impairment: A Comparison of Two Nordic Twin Cohorts

Venla S. Laitala, Jacob Hjelmborg, Markku Koskenvuo, Ismo Räihä, Juha O. Rinne, Kaare Christensen, Jaakko Kaprio and Karri Silventoinen

Heritability of Cortisol Regulation in Children

Per A. Gustafsson, Per E. Gustafsson, Henrik Anckarsäter, Paul Lichtenstein, Therese Ljung, Nina Nelson and Henrik Larsson

Investigation of Two Wnt Signalling Pathway Single Nucleotide Polymorphisms in a Breast Cancer-Affected Australian Population Plamena N. Gabrovska, Robert A. Smith, Larisa M. Haupt and Lyn R. Griffiths

Environmental and Genetic Contributions to Indicators of Oral Malodor in Twins

Walter A. Bretz, Aaron Biesbrock, Patricia M. Corby, Andrea L. Corby, Walter G. Bretz, Jennifer Wessel and Nicholas J. Schork

Twin-to-Twin Delivery Time: Neonatal Outcome of the Second Twin Susanne Schneuber, Eva Magnet, Josef Haas, Albrecht Giuliani, Thomas Freidl, Uwe Lang and Vesna Bjelic-Radisic

Variable Outcome in Quintuplets Pregnancy Based on Obstetric Care Grzegorz H. Bręborowicz, Anna Dera, Marta Szymankiewicz, Mariola Ropacka-Lesiak and Wiesław Markwitz

Pregnancy Outcome of Monochorionic Twins: Does Amnionicity Matter? Thiran Dias, Elena Contro, Basky Thilaganathan, Hina Khan, Cristina Zanardini, Samina Mahsud-Dornan and Amar Bhide

\section{News, Views, and Comments}

The Value of Twin Studies: A Response to Slate Magazine / Research

Nancy L. Segal 


\section{Book Review}

Someone Else's Twin: The True Story of Babies Switched at Birth Nancy Segal

Reviewed by Chris Prizeman and Naomi R. Wray, University of Queensland, Australia

\section{Erratum}

At the rear of this journal is a reproduction of the article entitled 'Estimation of the Contribution of Assisted and Non-Assisted Reproductive Technology Fertility Treatments to Multiple Births During the Past 30 Years in Japan: 1979-2008' by Syuichi Ooki published in Twin Research and Human Genetics Volume 14 Number 5 (October 2011).

Unfortunately due to a technical issue during production this article was not printed in its correct format.

The publisher would like to extend his apologies to Syuichi Ooki and the Societies for this error. 